\title{
MODEL KEPEMIMPINAN KEPALA RUANGAN MENURUT PANDANGAN PERAWAT PELAKSANA BERHUBUNGAN DENGAN RETENSI
}

\author{
Yulia Yasman ${ }^{1 *}$, Junaiti Sahar ${ }^{2}$, Tuti Nuraini ${ }^{2}$ \\ 1. Program Studi Magister, Fakultas Ilmu Keperawatan, Universitas Indonesia, Depok 16424, Indonesia \\ 2. Fakultas Ilmu Keperawatan, Universitas Indonesia, Depok 16424, Indonesia \\ *E-mail: yulia_yasman@yahoo.com
}

\begin{abstract}
Abstrak
Retensi perawat adalah hal penting untuk memelihara stabilitas tenaga kerja keperawatan. Namun, angka turnover perawat yang tinggi mengindikasikan rendahnya retensi perawat di Rumah Sakit Umum Daerah (RSUD) X di Jakarta. Di sisi lain, kepemimpinan berkontribusi hampir pada setiap kegiatan dalam organisasi. Penelitian ini bertujuan untuk mengetahui hubungan model kepemimpinan kepala ruangan menurut pandangan perawat pelaksana dengan retensi. Penelitian ini menggunakan desain deskriptif korelasi. Sampel berjumlah 166 perawat pelaksana. Hasil analisis menunjukkan proporsi perawat dengan tingkat retensi tinggi sebesar 50\%. Model kepemimpinan situasional, transformasional, transaksional, visioner, dan servant mempunyai hubungan yang bermakna dengan retensi perawat $(\mathrm{p}<$ $0,05)$. Model kepemimpinan yang paling berhubungan dengan retensi adalah model kepemimpinan transaksional $(\mathrm{OR}=$ 2,81). Model kepemimpinan memberikan pengaruh yang positif terhadap lingkungan kerja, kepuasan kerja, komitmen organisasi, dan kinerja perawat yang pada akhirnya akan meningkatkan retensi perawat sehingga perlu diimplementasikan dengan baik.
\end{abstract}

Kata kunci: Kepuasan kerja, komitmen organisasi, model kepemimpinan, retensi

\begin{abstract}
Leadership Model of Nurse' Unit Manager and Nurse Retention: the Staffs' Perception. Nurse retention is important to maintain the stability of nursing workforce. But, the high nurse turnover indicates low nurse retention in RSUD X at Jakarta. Other sides, leadership contributes to nearly every activity within organization. The research aims to determine the relationship of nurse unit manager's leadership models from the viewpoint of nursing staff to retention. The study used a descriptive correlation design. The sample consisted of 166 nurses. The result showed high retention of nurse proportion in 50\%. The situational, transformational, transactional, visionary, and servant leadership model had significant relationship with nurse retention $(p<0.05)$. The leadership model which has high correlation to retention was transactional leadership $(O R=2.881)$. Leadership model gives positive influence to work environment, job satisfaction, organizational commitment, and nurse performance which are finally increase nurse retention.
\end{abstract}

Keywords: Job satisfaction, leadership model, organizational commitment, retention

\section{Pendahuluan}

Kegiatan pelayanan keperawatan yang bermutu sangat bergantung pada kualitas dan kuantitas perawat yang bertugas (Suarli \& Bahtiar, 2002). Sumber Daya Manusia (SDM) rumah sakit termasuk perawat merupakan aset berharga bagi rumah sakit (Mosadeghrad, Ferli, Rosenberg, \& Duska, 2008; Strachota, Normandin, O’Brien, Clary, \& Krukow, 2003), karena tenaga keperawatan terbesar proporsinya di antara tenaga kesehatan lain di rumah sakit (Hogan, Moxham, \& Dwyer, 2007). Rumah sakit tidak akan berhasil tanpa karyawannya (Mosadeghrad, et al., 2008). Pengelolaan SDM perlu dilakukan dengan manajemen yang tepat.

Retensi perawat adalah kapasitas rumah sakit untuk mempertahankan tenaga perawat terampil dan berkualitas secara berkelanjutan agar tidak berniat meninggalkan organisasi sehingga stabilitas SDM terjaga dan produktifitas kerja 
meningkat (Dieleman, \& Harnmeijer, 2006; Tomey, 2009; Huber, 2010). Retensi dinilai menggunakan angka turnover (Dieleman, \& Harnmeijer, 2006; Huber, 2010).

Barlow dan Zangaro (2010) menekankan pentingnya mengantisipasi turnover untuk meningkatkan retensi perawat. Kegagalan meretensi perawatnya akan memberikan kerugian rumah sakit (Hayes, et al., 2006). Pergantian yang terlalu sering akan merendahkan moral perawat karena jurang yang diciptakan antara keberangkatan staf dan kedatangan penggantinya (Gillies, 1998). Beban kerja berlebihan terjadi bagi staf yang ada selama masa lowong (Gillies, 1998; Hayes, et al., 2006), kehilangan tenaga perawat yang berpengalaman (Stearns, 2012), dan akan menurunkan mutu pelayanan keperawatan (Gillies, 1998; Hayes, 2006).

Retensi perawat dipengaruhi oleh faktor organisasi, sosial, pekerjaan, dan individu perawat (Mosadeghrad, et al., 2008). Faktor organisasi yang memengaruhi retensi salah satunya adalah kepemimpinan (Mosadeghrad, et al., 2008). Kepemimpinan yang tepat dan efektif diperlukan untuk meretensi dan mengelola SDM menjadi aset organisasi (Muninjaya, 2004).

Peran kepemimpinan kepala ruangan sebagai manajer di lini depan sangat penting dalam mempengaruhi berbagai faktor dalam lingkungan kerja, serta dapat memengaruhi kepuasan staf dan retensi tenaga perawat (Sellgren, Kajermo, Ekvall, \& Tomson, 2008). Kepemimpinan kepala ruangan berhubungan dengan kepuasan kerja staf perawat (Shader, Broome, West, \& Nash, 2001), dan merupakan faktor kunci dalam retensi staf perawat (Ribelin, 2003). Peran kepemimpinan dalam upaya retensi perawat sudah dimulai sejak proses rekrutmen (Nickerson, 2002). Kepemimpinan menekankan pada peningkatan produktifitas dengan memaksimalkan efektifitas kerja (Marquis \& Huston, 2010). Namun, Kleinman (2004) menyebutkan masih sedikit penelitian mengenai perilaku dan model kepemimpinan kepala ruangan secara spesifik yang berkontribusi paling besar terhadap retensi staf perawat.
Angka turnover perawat RSUD X di Jakarta pada tahun 2010 sebesar 24\%, meningkat menjadi $39 \%$ pada tahun 2011, dan pada tahun 2012 dapat ditekan menjadi 18\%. Namun, angka ini masih cukup tinggi jika dibandingkan dengan standar angka turnover menurut Gillies (1998), yaitu $10 \%$.

Mosadeghrad, et al. (2008) menyebutkan bahwa titik kritis dari retensi adalah kepuasan kerja dan komitmen organisasi. Salah satu faktor organisasi yang berpengaruh terhadap retensi perawat adalah model kepemimpinan kepala ruangan. Berdasarkan hasil pengamatan dan survei, kepala ruangan cenderung menampilkan beberapa model kepemimpinan dalam menjalankan tugas dan fungsinya untuk mengatur dan mengelola ruang rawat yang menjadi tanggung jawabnya. Ada beberapa model kepemimpinan yang dapat diterapkan di rumah sakit yaitu model kepemimpinan situasional, transformasional, transaksional, visioner, dan servant (Kleinman, 2004; Hayes et al., 2006; Huber, 2010; Stearns, 2012).

Peneliti belum menemukan penelitian yang sama persis tentang hubungan model kepemimpinan kepala ruangan dengan retensi perawat. Pertanyaan penelitian ini adalah "Apakah ada hubungan model kepemimpinan kepala ruangan menurut pandangan perawat pelaksana dengan retensi di rumah sakit (RS)?”

\section{Metode}

Desain penelitian ini berupa penelitian deskriptif korelasi dengan pendekatan cross sectional. Sampel penelitian berjumlah 166 perawat pelaksana. Data dikumpulkan melalui kuesioner dan dianalisis secara komputerisasi.

\section{Hasil}

Hasil penelitian terkait karakteristik perawat dapat dilihat pada Tabel 1. Tabel 1 menunjukkan bahwa sebagian besar perawat memiliki karakteristik umur kurang dari 30 tahun $60,8 \%$, berjenis kelamin perempuan sebanyak $88 \%$, tingkat pendidikan vokasional sebanyak $89,2 \%$, status menikah sebanyak 
$52,4 \%$, berstatus pegawai tetap sebanyak $72,9 \%$, dan lama kerja kurang dari 5 tahun $57, \%$.

Variabel retensi terdiri atas dua subvariabel, yaitu kepuasan kerja dan komitmen organisasi. Gambaran retensi, kepuasan kerja, dan komitmen organisasi dapat dilihat pada Tabel 2.

Hasil analisis pada Tabel 2 menunjukkan bahwa perawat memiliki tingkat retensi tinggi sebanyak $50 \%$, berdasarkan aspek kepuasan kerja dan komitmen organisasi sebagian besar perawat pelaksana memiliki kepuasan kerja rendah sebanyak $54.8 \%$, namun komitmen organisasi tinggi 53\%.

Tabel 1. Karakteristik Perawat

\begin{tabular}{lcc}
\hline \multicolumn{1}{c}{ Variabel } & N & $\%$ \\
\hline Umur & & \\
a. $\geq 30$ tahun & 65 & 39,2 \\
b. $<30$ tahun & 101 & 60,8 \\
\hline Jenis kelamin & & \\
a. Perempuan & 146 & 88 \\
b. Laki-laki & 20 & 12 \\
Tingkat pendidikan & & \\
a. Vokasional & 148 & 89,2 \\
b. Profesional & 18 & 10,8 \\
Status pernikahan & & \\
a. Menikah & 87 & 52,4 \\
b. Belum menikah & 79 & 47,6 \\
Status kepegawaian & & \\
a. Pegawai tetap & 121 & 72,9 \\
b. Honorer & 45 & 27,1 \\
Lama kerja & & \\
a. $\geq 5$ tahun & 70 & 42,2 \\
b. <5 tahun & 96 & 57,8 \\
\hline
\end{tabular}

Tabel 2. Tingkat Retensi, Kepuasan Kerja, dan Komitmen Organisasi

\begin{tabular}{lcc}
\hline \multicolumn{1}{c}{ Variabel } & N & \% \\
\hline Retensi & & \\
a. Tinggi & 83 & 50 \\
b. Rendah & 83 & 50 \\
\hline Kepuasan kerja & & \\
a. Tinggi & 75 & 45,2 \\
b. Rendah & 91 & 54,8 \\
Komitmen Organisasi & & \\
a. Tinggi & 88 & 53 \\
b. Rendah & 78 & 47 \\
\hline
\end{tabular}

Hasil analisis pada Tabel 3 menunjukkan bahwa dari 166 perawat pelaksana mempunyai pandangan model kepemimpinan yang paling dominan ditampilkan oleh kepala ruangan adalah model kepemimpinan visioner, yaitu sebanyak $54.8 \%$. Di sisi lain, model kepemimpinan yang paling tidak dominan ditampilkan oleh kepala ruangan adalah model kepemimpinan servant, yaitu $41 \%$.

Hasil analisis bivariat model kepemimpinan dengan retensi dapat dilihat pada Tabel 4.

Tabel 3. Distribusi Model Kepemimpinan

\begin{tabular}{lcc}
\hline \multirow{2}{*}{ Model Kepemimpinan } & \multicolumn{2}{c}{ Menggunakan } \\
\cline { 2 - 3 } & $\mathrm{N}$ & $\%$ \\
\hline a. Situasional & 78 & 47 \\
b. Transformasional & 77 & 46,4 \\
c. Transaksional & 82 & 49,4 \\
d. Visioner & 91 & 54,8 \\
e. Servant & 68 & 41 \\
\hline
\end{tabular}

Tabel 4. Hubungan Model Kepemimpinan dengan Retensi

\begin{tabular}{|c|c|c|c|c|c|c|}
\hline \multirow{3}{*}{ Variabel } & \multicolumn{4}{|c|}{ Retensi } & \multirow{3}{*}{ OR } & \multirow{3}{*}{$\mathbf{P}$} \\
\hline & \multicolumn{2}{|c|}{ Rendah } & \multicolumn{2}{|c|}{ Tinggi } & & \\
\hline & $\Sigma$ & $\%$ & $\Sigma$ & $\%$ & & \\
\hline Situasional & & & & & 3,677 & $70,000^{*}$ \\
\hline a.Ya & 52 & 66,7 & 26 & 33,3 & & \\
\hline b.Tidak & 31 & 35,2 & 57 & 64,8 & & \\
\hline Total & 83 & 50 & 83 & 50 & & \\
\hline Transformasional & & & & & 3,14 & $0,001 *$ \\
\hline a.Ya & 50 & 64,9 & 27 & 35,1 & & \\
\hline b.Tidak & 33 & 37,1 & 56 & 62,9 & & \\
\hline Total & 83 & 50 & 83 & 50 & & \\
\hline Transaksional & & & & & 4,55 & $0,000^{*}$ \\
\hline a.Ya & 56 & 68,3 & 26 & 31,7 & & \\
\hline b.Tidak & 27 & 32,1 & 57 & 67,9 & & \\
\hline Total & 83 & 50 & 83 & 50 & & \\
\hline Visioner & & & & & 4,9 & $0,000^{*}$ \\
\hline a.Ya & 61 & 67,0 & 30 & 33,0 & & \\
\hline b.Tidak & 22 & 29,3 & 53 & 70,7 & & \\
\hline Total & 83 & 50 & 83 & 50 & & \\
\hline Servant & & & & & 3,85 & $0,000^{*}$ \\
\hline a.Ya & 47 & 69,1 & 21 & 30,9 & & \\
\hline b.Tidak & 36 & 36,7 & 62 & 63,3 & & \\
\hline Total & 83 & 50 & 83 & 50 & & \\
\hline
\end{tabular}


Tabel 5. Pemodelan Akhir Multivariat

\begin{tabular}{lcccc}
\hline & $\mathbf{B}$ & $\mathbf{p}$ & OR & CI 95\% \\
\hline a.Transaksional & 1,056 & 0,004 & 2,881 & $1,407-5,899$ \\
b.Visioner & 1,169 & 0,002 & 3,220 & $1,564-6,631$ \\
Constant & $-3,285$ & 0,000 & 0,037 & -
\end{tabular}

*bermakna pada $\alpha=0,05$

Hasil analisis pada Tabel 4 menunjukkan bahwa ada hubungan yang bermakna antara kepemimpinan situasional, transformasional, transaksional, visioner, dan servant dengan retensi perawat $(\alpha=0,05)$. Hasil pemodelan akhir analisis regresi logistik berganda dapat dilihat pada Tabel 5.

Hasil akhir analisis multivariat menunjukkan bahwa model kepemimpinan yang paling berhubungan dengan retensi adalah model kepemimpinan transaksional $(\mathrm{OR}=2,881)$ diikuti oleh model kepemimpinan visioner $(\mathrm{OR}=3,220)$.

\section{Pembahasan}

Rendahnya komitmen afektif menunjukkan bahwa perawat pelaksana belum memiliki keterikatan emosional dengan organisasi sehingga hal ini akan berpengaruh terhadap motivasi internal perawat. Perawat pelaksana belum merasa menjadi bagian penting dari RS dan tidak merasa masalah yang dihadapi oleh RS juga menjadi masalah untuk perawat. Peneliti melihat hal ini sebagai sesuatu yang wajar mengingat masa kerja perawat yang masih di bawah lima tahun dan masih cukup banyak perawat pelaksana di RSUD X yang belum berstatus pegawai tetap.

Model kepemimpinan situasional: delegating tepat diterapkan pada tingkat kesiapan pengikut tertinggi yaitu jika karyawan mampu dan bersedia, sehingga pemimpin tidak perlu melakukan banyak hal atau cukup mendelegasikan saja (delegating) (Robbins $\&$ Coulter, 2007). Namun, jika dilihat dari usia dan lama kerja perawat di RSUD X mengindikasikan bahwa gaya kepemimpinan delegating belum cukup sesuai untuk diterapkan. Furtado, Graca, Batista, dan Silva (2011) menyebutkan bahwa gaya kepemimpinan directing dan coaching sangat dibutuhkan oleh perawat yang masih muda dan pengalaman kerja yang minim.

Kepemimpinan transformasional kepala ruangan berdampak langsung terhadap kinerja perawat Hasil ini juga diperkuat oleh penelitian Sitanggang (2010), yaitu mana ada hubungan yang bermakna antara kepemimpinan transformasional dengan kinerja perawat pelaksana. Kunci untuk efektifitas kinerja adalah tampilan perilaku model kepemimpinan transformasional (Casida dan Pinto-Zipp, 2008). Biasanya, seorang pemimpin transformasional akan mempunyai kharisma, berani mengambil risiko, dan berfikir di luar kotak, berbakat untuk memotivasi orang lain sambil bertindak sebagai role model dan mentor bagi pengikutnya (Northouse, 2010).

Model kepemimpinan transformasional juga mempunyai hubungan yang signifikan dengan lingkungan kerja psikososial dalam keperawatan. Hasil penelitian Malloy dan Penprase (2010), ada korelasi yang signifikan antara kepemimpinan transformasional dengan dimensi lingkungan kerja psikososial yaitu nilai organisasi, hubungan personal-leader, hubungan personal-kolega, kerja organisasi, keluaran individu, dan kepemimpinan.

Elemen kunci dari kepemimpinan transaksional, contingent reward menempatkan fokus yang lebih besar terhadap penghargaan karyawan untuk pekerjaan mereka. Kepala ruangan menggunakan komponen contingent reward $68,1 \%$. Strategi dalam contingent reward dapat berupa pujian lisan, insentif keuangan, dan pengakuan publik untuk memotivasi karyawan (Northouse, 2010). Kepala ruangan lebih nyaman menggunakan model kepemimpinan transaksional untuk digunakan dalam situasi tertentu (Casida dan Parker, 2011).

Adanya hubungan antara kepemimpinan transaksional dan retensi di RSUD X dimungkinkan karena kepala ruangan telah menampilkan kepemimpinan transaksional, walaupun baru dirasakan oleh sebagian perawat $(49,4 \%)$. Komponen kepemimpinan transaksional yang dominan ditampilkan oleh kepala ruangan adalah menggunakan elemen Managing Basic 
Education (MBE) aktif. Artinya kepala ruangan di RSUD X bekerja dan mengevaluasi kinerja perawat pelaksana berdasarkan standar yang telah ditetapkan.

Kepala ruangan telah menampilkan masingmasing komponen kepemimpinan visioner itu, yaitu komponen yang dominan adalah kepala ruangan di RSUD X menampilkan komunikasi yang baik sebanyak 77,7\%. Hasil didukung oleh penelitian Yatnikasari (2010), yaitu ada hubungan yang bermakna antara komunikasi dengan komitmen organisasi perawat pelaksana.

Kepala ruangan di RSUD X telah menjalankan peran informasional terkait dengan komponen komunikasi. Teknik komunikasi yang digunakan secara tepat dapat menciptakan hubungan kerja yang kondusif antara kepala ruangan dan stafnya (Suarli \& Bahtiar, 2002). Kepemimpinan visioner dipengaruhi oleh tiga domain, yaitu sifat (trait), situasi (situation), dan perilaku (behavior). Ada tiga sifat utama yang harus dimiliki oleh seorang pemimpin visioner, yaitu cognitive complexity, emotional intelligence, dan leader self-efficacy (Petrides, Frederickson, \& Furnham, 2004).

Sebagian besar kepala ruangan belum menggunakan model kepemimpinan servant dalam mengelola unit yang menjadi tanggung jawabnya. Robert Grennleaf mengembangkan hal yang menjadi paradoxical dalam pendekatan kepemimpinan yang dinamakan servant leadership. Grennleaf menjelaskan bahwa kepemimpinan dapat memberikan pengetahuan pada seseorang untuk memberikan pelayanan dalam situasi darurat, apabila individu mendapatkan kesulitan dalam pekerjaannya akan datang ke pemimpin untuk meminta dicarikan jalan keluarnya. Pimpinan akan fokus pada kebutuhan staf dan membantu untuk lebih dapat mengetahui, lebih bebas, dan mempunyai lebih otonomi serta lebih menyukai pelayanan yang diberikan, dengan demikian tindakan yang diberikan pimpinan akan memperkaya wawasan staf karena mendapatkan pengalaman yang nyata (Sumijatun, 2011).

Model kepemimpinan transaksional dan visioner berpengaruh besar terhadap retensi perawat pelaksana di RSUD X. Perawat pelaksana di RSUD X membutuhkan model kepemimpinan transaksional dan visioner karena akan mendukung peningkatan kepuasan kerja dan komitmen organisasi. Perawat pelaksana menilai kepemimpinan transaksional kepala ruangan tidak lagi berfokus pada contingent reward, tetapi perawat membutuhkan perilaku manajemen eksepsi kepala ruangan. Hal ini dibuktikan dari komponen kepemimpinan transaksional yang paling dominan adalah komponen menggunakan MBE aktif 77,1\%. Artinya kepala ruangan melakukan penilaian kinerja staf secara akurat, sesuai dengan standar yang ada yang akan meningkatkan retensi. Hal ini disebabkan oleh penilaian kepala ruangan akan mempengaruhi penilaian manajemen untuk menetapkan status kepegawaian seorang perawat pelaksana. Selain itu, manajemen eksepsi aktif merupakan bagian dari supervisi.

Supervisi berperan penting untuk mempertahankan segala kegiatan dapat dilaksanakan dengan baik (Swansburg, 2002). Sementara itu, perawat pelaksana mempunyai pandangan kepala ruangan. Menggunakan komponen contingent reward sebesar $68,1 \%$. Strategi dalam contingent reward dapat berupa pujian lisan, insentif keuangan, dan pengakuan publik untuk memotivasi karyawan (Northouse, 2010).

Model kepemimpinan visioner juga berpengaruh terhadap retensi perawat setelah dikontrol variabel perancu. Hasil ini menggambarkan bahwa perawat pelaksana RSUD X membutuhkan kepala ruangan yang mempunyai tujuan yang jelas di masa depan. Komunikasi adalah dasar interaksi antara pemimpin dan pengikut, dimana pemimpin visioner akan memfokuskan perhatian dan membuat jelas visi yang ingin dicapai (Martini, 2008). Kemampuan mengungkapkan visi itu bukan hanya secara verbal melainkan juga melalui perilaku dalam berbagai konteks kepemimpinan (Robbins \& Coulter, 2007). Perawat yang mempunyai pandangan kepala ruangan menggunakan model kepemimpinan visioner berharap kepala ruangan mampu membawa stafnya lebih maju dan berkembang sejalan dengan visi dan misi RS. 


\section{Kesimpulan}

Perawat pelaksana mempunyai pandangan bahwa model kepemimpinan yang dominan ditampilkan oleh kepala ruangan adalah model kepemimpinan visioner. Model kepemimpinan yang paling dominan berhubungan dengan retensi adalah model kepemimpinan transaksional diikuti oleh model kepemimpinan visioner setelah dikontrol oleh karakteristik perawat.

Sistem pemberian hadiah berbasis beban kerja dan kinerja perawat baik dalam bentuk finansial maupun nonfinansial perlu diupayakan RS. Kebijakan terkait sistem jenjang karier berbasis kompetensi juga perlu disusun dalam upaya meningkatkan motivasi dan kinerja perawat. Penetapan kepala ruangan juga perlu memperhatikan aspek kepemimpinannya. Penelitian lanjutan terkait faktor lain yang memengaruhi retensi perlu diteliti serta perlu dilakukan replikasi penelitian ini di rumah sakit swasta dan militer (INR, HH).

\section{Referensi}

Barlow, K.M., \& Zangaro, G.A. (2010). Metaanalysis of the reliability and validity of the anticipated turnover scale across studies of registered nurses in the United States. Journal of Nursing Management, 18, 862873. Doi: 10.1111/j.1365-2834.2010.01171.x.

Casida, J., \& Parker, J. (2011). Staff nurse perceptions of nurse manager leadership styles and outcomes. Journal of Nursing Management, 19, 478-486. doi: 10.1111/ j.1365-2834.2011.01252.x

Casida, J., \& Pinto-Zipp, G. (2008). Leadershiporganizational culture relationship in nursing units of acute care hospitals. Nursing Economics 26 (1), 7-15.

Furtado, L. C., Graca, D. M., Batista, \& Silva, F. (2011). Leadership's impact in turnover and career abandonment intention: the Azorean hospital nurses case. Hospital Topics, 89 (3), 51-58. Doi: 10.1080/00185868.2011.596797.

Gillies, D.A. (1998). Manajemen keperawatan: suatu pendekatan sistem (edisi 2). (Dika
Sukmana \& Rika Widya Sukmana, Penerjemah). Jakarta: Penerbit UI.

Hayes, L. J., O'Brien-Pallas, L., Duffield, C., Shamian, J., Buchan, J., Hughes, F., Laschinger, H.K.S., North, N., \& Stone, P.W. (2006). Nurse turnover: A literature review. International Journal of Nursing Studies, 43, 237-263. Doi: 10.1016/j.ijnurstu. 2005.02.007.

Hogan, P., Moxham, L., \& Dwyer, T. (2007). Human resource management strategies for the retention of nurses in acute care settings in hospital in Australia. Contemporary Nurse, 24, 189-199.

Huber, D.L. (2010). Leadership and nursing care management (4th Ed.). Philadelpia: Saunders Elsevier.

Kleinman, C. (2004). The relationship between managerial leadership behaviors and staff nurse retention. Hospital Topics: Research and Perspectives on Healthcare, 82 (4), 2-9.

Laschinger, H.K., Finegan, J., Shamian, J., \& Wilk, P. (2004). A longitudinal analysis of the impact of workplace empowerment on work satisfaction. Journal of Organizational Behaviour, 25, 527-545.

Laschinger, H.K., Leiter, M., Day, A., \& Gillin, D. (2009). Workplace empowerment, incivility, and burnout: impact on staff nurse recruitmen and retention outcomes. Journal of Nursing Management, 17, 302-311. Doi:10.1111/j.1365-2834.2009.00999.x.

Malloy T, \& Penprase B. (2010). Nursing leadership style and psychosocial work environment. Journal of Nursing Management, 18, 715725. Doi: 10.1111/j.1365-2834.2010.01094.x.

Marquis, B.L., \& Huston, C.J. (2010). Kepemimpinan dan manajemen keperawatan: Teori dan aplikasi (edisi 4). (Widyawati, Wilda Eka Handayani, \& Fruriolina Ariani, Penerjemah). Jakarta: EGC.

Martini, P.H. (2008). Toward an integrated model of visionary leadership: A multilevel study. Diperoleh dari http://www.regent.edu/acad/ global/publications/dissertations/martini2008. $\mathrm{cfm}$. 
Mosadeghrad, A. M., Ferli, M., Rosenberg, \& Duska. (2008). A study of the relationship between job satisfaction, organizational commitment and turnover intention among hospital employee. Health Service Management Research, 21, 211-227. doi: 10.1258/hsmr. 2007.007015.

Muninjaya, A.A.G. (2004). Manajemen kesehatan. Jakarta: EGC.

Nickerson, C. (2002). Recruitmen and retention. Nursing management, 9: 8-13.

Northouse P.G. (2010). Leadership theory and practice (5th ed). Los Angeles: Sage.

Petrides, K.V., Frederickson, N., \& Furnham, A. (2004). The role of trait emotional intelligence in academic performance and deviant behavior at school. Personality and Individual Differences, 36, 277-293.

Ribelin, P. (2003). Retention reflects leadership styles. Nursing Management 34(8), 18-19.

Robbins, S.P., \& Coulter, M. (2007). Manajemen (edisi 8). (Harry Slamet \& Ernawati Lestari: Penerjemah). Jakarta: Indeks.

Sellgren, S.F., Kajermo, K.N., Ekvall, G., \& Tomson, G. (2008). Nursing staff turnover at a Swedish university hospital: an exploratory study. Journal of Clinical Nursing 18, 31813189. doi: 10.1111/j.1365-2702.2008.02770.x.

Shader, K., Broome, M., West,M., \& Nash. (2001). Factors influencing satisfaction and anticipated turnover for nurses in an academic medical center. Journal of Nursing Administration, 31 (4), 210-216.

Sitanggang, L. (2010). Hubungan karakteristik individu, kepemimpinan transformasional dan transaksional kepala ruangan dengan kinerja perawat di P.K St.Carolus Jakarta (Tesis, Tidak dipublikasikan). Fakultas Ilmu Keperawatan Universitas Indonesia, Jakarta.

Stearns, M. (2012). The relationship of leadership behaviors to staff $R N$ job satisfaction and retention. Grand Canyon University, ProQuest Dissertations Publishing. Diperoleh dari: http://search.proquest.com/docview/1038375 468/13BD6BD2C5C2C9E1E49/2?accountid $=17242$.

Strachota, E., Normandin, P., O'Brien, N., Clary, M., \& Krukow, B. (2003) Reason registered nurse leave or change employment status. Journal of Nursing Administration, 33 (2), 111-117.

Suarli, S., \& Bahtiar, Y. (2002). Manajemen keperawatan dengan pendekatan praktis. Jakarta: Penerbit Erlangga.

Sumijatun. (2011). Membudayakan etika dalam praktik keperawatan. Jakarta: Salemba Medika.

Tomey, A.M. (2009). Guide to nursing management and leadership (8th Ed.). Vancouver: Mosby Elsevier.

Tourangeau, A.E., Cummings, G., Cranley, L.A., Ferron, E.M., \& Harvey, S. (2010). Determinants of hospital nurse intention to remain employed: broadening our understanding. Journal of Advanced Nursing 66 (1), 22-32. Doi: 10.1111/j.1365-2648.2009.05190.x.

Dieleman, M., \& Harnmeijer, J.M. (2006). Improving health worker performance: in search of promising practices. Geneva: WHO, Evidence and Information for Policy, Department of Human Resources for Health. Diperoleh dari http://www.who.int/hrh/ resources/improving_hw_performance.pdf. 